https://doi.org/10.30681/real.v14.6052

\title{
AS NOVAS PRÁTICAS DE GESTÃO ESCOLAR EM TEMPOS DE PANDEMIA: UM ESTUDO DO PLANO PEDAGÓGICO ESTRATÉGICO DE APOIO AS ESCOLAS (PPEAE) DA ESCOLA ESTADUAL “22 DE MAIO” DA CIDADE DE RIO BRANCO - MT.
}

\author{
Adriany Sabrine FERREIRA (SEDUC-MT) ${ }^{1}$
}

\begin{abstract}
Resumo: Este artigo trata-se de um estudo acerca do Plano Pedagógico Estratégico de Apoio às Escolas da Escola Estadual "22 de Maio" do município de Rio Branco - MT em tempos de pandemia. Diante do atual cenário na educação em todo país, mais especificamente neste artigo sobre a educação básica, foi necessária a elaboração de um plano estratégico específico para atender aos alunos. O plano consiste em verificar o acesso ou não à internet de professores e alunos, a metodologia a ser utilizada para que $100 \%$ dos alunos possam ser atendidos sem prejuízos no fim do ano letivo. Em tempos de pandemia, é preciso realinhar a relação professor-aluno, gestão-professor, gestãoaluno e aluno-aluno. Este artigo foi desenvolvido no sentido de contribuir para o conhecimento dos interessados na educação em tempos de pandemia demonstrando a realidade de uma escola do interior.
\end{abstract}

Palavras-Chave: Gestão escolar. Pandemia. Plano Pedagógico Estratégico. Educação.

\begin{abstract}
This article is about a study about the Pedagogical Strategic Plan to Support Schools of the State School "22 de Maio" in the city of Rio Branco - MT in times of pandemic. Given the current scenario in education across the country, more specifically in this article on basic education, it was necessary to draw up a specific strategic plan to serve students. The plan consists of checking whether or not teachers and students have access to the internet, the methodology to be used so that $100 \%$ of students can be served without prejudice at the end of the school year. In times of pandemic, it is necessary to realign the teacher-student, management-teacher, management-student and student-student relationships. This article was developed in order to contribute to the knowledge of those interested in education in times of pandemic, demonstrating the reality of a school in the interior.
\end{abstract}

Keywords: School management. Pandemic. Strategic Pedagogical Plan. Education.

\section{Introdução}

O mundo não estava preparado para lidar com a educação em tempos de pandemia. Deixar de ir à escolar tornou-se tema polêmico em quase todos os países do mundo conforme se acompanha nas notícias trazidas pela mídia. Os pais, os professores, os gestores, o governo... ninguém esperava por isso! E agora? Como realinhar a ordem deste "novo normal" nos moldes da educação básica?

Diante desta problemática, o papel da gestão escolar é imprescindível para que toda a comunidade venha a ser alcançada e cada aluno possa ser atendido em sua particularidade.

\footnotetext{
${ }^{1}$ Pós-graduada em gestão escolar pela Faculdade Venda Nova do Imigrante. E-mail: adrianysabrine88@ gmail.com
} 


\section{Revista de Estudos Acadêmicos de Letras}

De acordo com a Lei de Diretrizes e Bases (Lei n 9.394/96), a gestão democrática é definida:

Art. 14. Os sistemas de ensino definirão as normas da gestão democrática do ensino público na educação básica, de acordo com as suas peculiaridades e conforme os seguintes princípios: I - participação dos profissionais da educação na elaboração do projeto pedagógico da escola; II - participação das comunidades escolar e local em conselhos escolares ou equivalentes.

Nessa mesma perspectiva, Dourado (2007) diz que

“desde a redemocratização do país, houve mudanças acentuadas na educação brasileira, com destaque para a aprovação e promulgação da Constituição Federal de 1988, que garantiu uma concepção ampla de educação e sua inscrição como direito social inalienável (...)".

A Secretaria de Estado de Educação do Estado de Mato Grosso - SEDUC/MT, diante da impossibilidade do retorno às aulas presencias, elaborou um Plano Estratégico de Apoio às Escolas (PPEAE) para que os alunos pudessem ser atendidos com atividades e acompanhados por seus professores, de forma remota.

Tal situação é novidade para todos que trabalham na área da educação básica e requer um estudo a mais desta nova realidade.

Diante disso, evidenciou-se a necessidade de elaborar o presente artigo com base na situação em que estamos vivenciando nos dias de hoje, em tempos de pandemia a fim de contribuir para a área da educação.

\section{Desenvolvimento}

Para realizarmos uma breve abordagem sobre a educação à distância em tempos de pandemia, foi realizado um estudo sobre o Plano Pedagógico Estratégico de Apoio às Escolas PPEAE da Escola Estadual "22 de Maio” do município de Rio Branco - MT.

O município de Rio Branco - MT se localiza a $336 \mathrm{~km}$ da capital Cuiabá e tem cerca de 5.061 habitantes (wikipedia, 2020). O Município possui uma escola municipal de educação infantil, uma escola municipal que atende o ensino fundamental e duas escolas estaduais, onde uma atende apenas no período diurno o ensino fundamental e ensino médio e a outra (objeto 


\section{Revista de Estudos Acadêmicos de Letras}

deste estudo) atende apenas no período noturno o ensino médio regular e a educação de jovens e adultos.

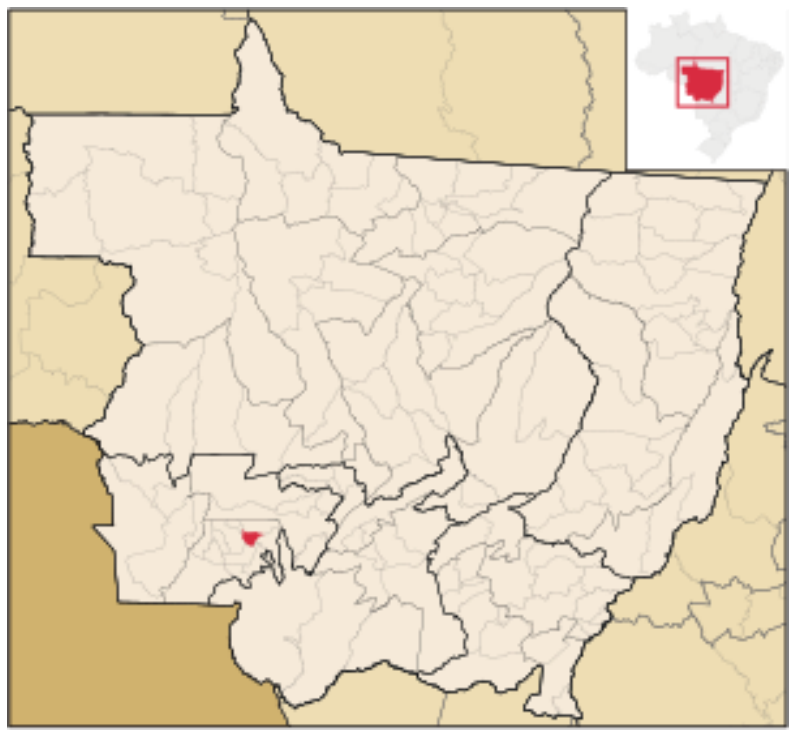

Figura 1. Localização de Rio Branco - MT. (Fonte: https://pt.wikipedia.org/wiki/Rio_Branco_Mato_Grosso,

2020)

Devido ao grande avanço do Coronavírus em nosso país, o Estado de Mato Grosso, através do Decreto n 407 de 16 de Março de 2020, determina medidas emergenciais para o enfrentamento da pandemia e neste documento decidiu antecipar o recesso escolar para 23/03/2020 com duração até 05/04/2020. A partir do dia 06/04/2020 as aulas foram suspensas e permaneceram até o dia 02/08/2020.

O governo federal juntamente com o Ministério da Educação emitiu a Medida Provisória n 934 de 01 de abril de 2020, publicada no Diário Oficial da União em edição extra, que desobrigava as escolas de cumprirem o mínimo de 200 (duzentos) dias letivos previstos na Lei de Diretrizes e Bases da Educação n 9.394/96, porém com a obrigatoriedade de cumprir as 800 (oitocentas) horas anuais para cada fase/série/ano escolar.

Assim, baseado neste documento, o Conselho Estadual de Educação do Estado de Mato Grosso publicou a Resolução Normativa no 003/2020 no Diário Oficial do Estado em 19 de junho de 2020, seguindo as mesmas diretrizes, passando a adotar apenas como obrigatório as 800 


\section{Revista de Estudos Acadêmicos de Letras}

(oitocentas) horas anuais. Para tal atendimento, o calendário escolar foi reorganizado e readequado em todas as unidades escolares estaduais.

Nesta mesma resolução normativa, o CEE-MT, determina:

Art.10. No entanto, enquanto durar as condições de isolamento social, as instituições pertencentes ao Sistema Estadual de Ensino que optarem por desenvolver atividades pedagógicas não presenciais, devem elaborar um Plano Pedagógico Estratégico e encaminhar aos órgãos supervisores: Assessoria Pedagógica (SEDUC) para a Educação Básica e a Superintendência da Secretaria de Estado de Ciência, Tecnologia e Inovação (SECITECI), para a Educação Profissional e Superior pública, no prazo de até 30 dias, após a publicação dessa Resolução

Tendo esta resolução normativa, sido homologada pela Secretária de Estado de Educação, todas as escolas estaduais adotaram do PPEAE. Após a publicação da resolução, a Secretaria de Estado de Educação - SEDUC/MT teve 30 (trinta) dias para elaborar um plano estratégico para que os alunos da rede estadual fossem atendidos de forma remota e não ficassem prejudicados quanto ao conteúdo a ser ministrado durante o ano letivo de 2020. Cada escola adequou o modelo do plano à sua realidade. As aulas remotas tiveram início em 03/08/2020.

O PPEAE consiste em realizar um levantamento de todos os alunos matriculados na unidade escolar, elencando quais alunos tem condições de serem atendidos através do acesso à internet em aulas on line na plataforma Teams e os alunos que não possuem acesso à internet e optam por atendimento por meio de material impresso (apostilas).

O modelo do PPEAE segue desta forma:

- Identificação da unidade escolar;

- Etapas e modalidades de educação que a escola oferta;

- Objetivos;

- Metas;

- Análise situacional (recursos tecnológicos da escola, dos professores e dos alunos;

- Metodologia;

- Cronograma;

- Divulgação e

- Avaliação da Aprendizagem.

Para Gandim (2001) 


\title{
Revista de Estudos Acadêmicos de Letras
}

\begin{abstract}
A principal característica do que hoje se chama Planejamento Participativo não é o fato de nele se estimular a participação das pessoas. Isto existe em quase todos os processos de planejamento: não há condições de fazer algo na realidade atual sem, pelo menos, pedir às pessoas que tragam sugestões.
\end{abstract}

Neste sentido, para elaboração do PPEAE, envolveram-se a gestão escolar e também os professores da educação básica para que tal estratégia fosse alinhada com a realidade da unidade escolar.

A EE 22 de Maio, atualmente, atende a demanda de Educação de Jovens e Adultos e também o Ensino Médio Regular. A escola tem seu funcionamento no período noturno. Devido o acesso à internet não ser uma realidade de todos os alunos de nossa comunidade e, também, pela maioria absoluta optar pelo atendimento através do material impresso, a escola decidiu atender todos os alunos com apostilas. Esse material é elaborado pelo professor de cada disciplina e visa atender o aluno mensalmente. Uma opção para que o aluno esclareça suas dúvidas são os grupos de Whatsapp, um para cada série/fase/ano, onde grande parte dos alunos interagem com o professor da sua disciplina de acordo com a organização do horário escolar.

No e-mail institucional da escola, foram criadas pastas no One Drive, onde o professor e a gestão inserem documentos pertinentes ao momento, como por exemplo todo o material produzido pelo professor, seu planejamento, além de ofícios, atas, registros em geral para organização e acompanhamento da equipe gestora.

Diante da nossa realidade de distanciamento social, a gestão escolar realiza reuniões semanais com os professores através da plataforma Teams, para repasse dos documentos atuais que são encaminhados pela mantenedora, elaboração de novas estratégias e também compartilhamento de dúvidas e experiências ao longo desta caminhada em tempos de pandemia.

A volta às aulas à distância tem sido um grande desafio para nossa realidade da educação básica, mesmo tendo vários meios de divulgação como: propagandas volantes, propagandas de rádio, comunicados via redes sociais, ligações telefônicas.

Em tempos de pandemia, a realidade da educação tomou nova forma e muitos ainda estão de readequando ao "novo normal".

\section{Conclusão}




\section{Revista de Estudos Acadêmicos de Letras}

Não há como negar que estamos diante de um "novo normal" em nossa sociedade em tempos de pandemia.

É preciso se adequar aos novos moldes para que haja interação e efetivação no ensino da educação em todo país, principalmente da educação básica.

Realinhar a ordem do processo de ensino-aprendizagem é essencial para que a gestão escolar juntamente com todos profissionais da educação possam seguir adiante rumo aos novos tempos.

Para isso, é preciso primeiramente planejar, traçando metas e objetivos que venham a atender a comunidade escolar em sua totalidade.

Pois como diz FREIRE (2000) "Se a educação sozinha não transforma a sociedade, sem ela tampouco a sociedade muda". A educação deve ser tratada de forma específica, valorizada e colocada nos primeiros lugares da vida de cada ser humano, mesmo diante de tempos tão adversos.

\section{Referências}

BRASIL. Diário Oficial do Estado de Mato Grosso. Decreto no 407 de 16 de março de 2020. Disponível em: <https://www.iomat.mt.gov.br/verpdf/15835/\#/p:2/e:15835?find=DECRETO\%20N\%C2\%BA\%20407,\%20DE\%2016\%20DE\%20 MAR\%C3\%87O\%20DE\%202020> Acesso em 14 de setembro de 2020.

BRASIL. Diário Oficial do Estado de Mato Grosso. RESOLUÇÃO NORMATIVA No 003/2020-CEE/MT. Disponível em <https://www.iomat.mt.gov.br/verpdf/15935/\#/p:16/e:15935?find=resolucao> Acesso em 14 de setembro de 2020.

BRASIL. Diário Oficial da União. Medida Provisória no 934 de 01 de abril de 2020. Disponível em: $<$ https://pesquisa.in.gov.br/imprensa/jsp/visualiza/index.jsp?jornal=600\&pagina $=1 \&$ data $=01 / 04 /$ 2020\&totalArquivos=1> Acesso em 14 de setembro de 2020.

BRASIL. Lei no 9.394, de 20 de dezembro de 1996. Estabelece as diretrizes e bases da educação nacional. Senado Federal, Brasília, DF, 2005. Disponível em: 
<https://www2.senado.leg.br/bdsf/bitstream/handle/id/70320/65.pdf> Acesso em: 29 de julho de 2020.

DOURADO, Luiz Fernando. Políticas e gestão da educação básica no Brasil: limites e perspectivas. Educ. Soc., Campinas, vol. 28, n. 100 - Especial, p. 921-946, out. 2007 Disponível em <https://www.scielo.br/pdf/es/v28n100/a1428100.pdf> Acesso em 03 de setembro de 2020.

FREIRE, Paulo. Pedagogia da indignação: cartas pedagógicas e outros escritos. 1. ed. São Paulo: Editora UNESP, 2000.

GANDIN, Danilo. A posição do planejamento participativo entre as ferramentas de intervenção na realidade. Currículo sem Fronteiras, v.1, n.1, pp.81-95, Jan/Jun 2001. Disponível em:< https://www.ets.ufpb.br/pdf/2013/2\%20S1\%20Gestao\%20Estrategica\%20\%20IFES/GANDIN_A\%20posição\%20do\%20planejamento\%20participativo.pdf > Acesso em 03 de setembro de 2020 .

Rio Branco (Mato Grosso) In: Wikipedia. Disponível em: <https://pt.wikipedia.org/wiki/Rio_Branco_(Mato_Grosso)>. Acesso em: 14 de setembro de 2020. 